\title{
Erratum to: Post-Separation Abuse of Women and their Children: Boundary-Setting and Family Court Utilization among Victimized Mothers
}

\author{
April M. Zeoli • Echo A. Rivera • Cris M. Sullivan • \\ Sheryl Kubiak
}

Published online: 17 October 2013

(C) Springer Science+Business Media New York 2013

Erratum to: J Fam Viol (2013) 28:547-560

DOI 10.1007/s10896-013-9528-7

The above authors missed to include the Acknowledgment section of the original article. The Acknowledgment should read as follows:

This study was funded by a grant from NIMH (R24MH75941), by the USDA National Institute of Food and Agriculture, Hatch project number MICL02202, and by Award Number K12HD065879 from the Eunice Kennedy Shriver National Institute Of Child Health and Human Development. The content is solely the responsibility of the authors and does not necessarily represent the official views of the National Institutes of Health or USDA.

The online version of the original article can be found at http:// dx.doi.org/10.1007/s10896-013-9528-7.

A. M. Zeoli $(\bowtie)$

School of Criminal Justice, Michigan State University,

540 Baker Hall, East Lansing, MI 48824, USA

e-mail: zeoli@msu.edu

E. A. Rivera $\cdot$ C. M. Sullivan

Psychology Department, Michigan State University,

130 Psychology Building, East Lansing, MI 48824, USA

S. Kubiak

School of Social Work, Michigan State University, 110 Baker Hall,

East Lansing, MI 48824, USA 